\title{
(Improving Health and Safety Management in the Saudi Arabian Oil and Gas Construction Project)
}

\author{
[ Reem Alamri ]
}

\begin{abstract}
Health and safety issues have always been a major problem in the oil and gas construction projects. It is found to be one of the dangerous industries, which has adverse impact on the health and safety related issues. Several efforts have been made to address this problem, but there is a lot of scope for the improvement of health and safety management. The article explores health and safety issues in relation to the oil and gas industry in Saudi Arabia. This article identifies all the safety and health issues, as well as, its adverse effect on human lives. The article also reflects several work related hazards that are concerned with oil and gas projects and the possible measures for preventing such health and safety risks.
\end{abstract}

\section{Introduction}

In the oil and gas industry, health and safety management is one of the most vital constituents as the chemicals and harmful end products that are associated with the production of gas and oil pose a serious threat to the health and safety of workers. Saudi Arabia is one of the wealthiest countries of the world because it has extensive oil resources. The world consumes millions of barrels of petroleum or crude oil every day, and the oil and gas resources contribute a huge part in the world economy (Tam, Zeng and Deng, 2004). The oil and gas industry is a main contributor to the Saudi economy; therefore, health and safety management becomes a crucial factor that needs to be addressed by the nation.

There are several hazards in the oil and gas industry such as safety, injury, health and illness hazards. Fire might cause interruptions in the oil production and accidents might occur that can cause hazards to humans and the environment, as well as, it will also lead to huge economic losses (Oloke, Yu and Heesom, 2007). Health and safety of the employees of oil and gas industry is always at stake as numerous activities such as chemical use within the industries cause harm. There are several processes such as cementing, stimulation, drilling and production that require improvement in the health and safety management strategies (Karmis, 2001).

(Reem Alamri)

University of Wolerhampton

United Kingdom

\section{Objective}

The main objective of this article is to analyse the health and safety issues and the ways of improving the health and safety management in the Saudi Arabian oil and gas construction projects.

\section{Review of Literatures}

According to Stellman (1998), protection of humans from physical injury is known as safety. Health and safety is a set of rules and procedures intended to protect people from accidents or injury caused at the workplaces. There are several safety and injury hazards such as fire, explosion, vehicle accident, slips and falls due to uneven surface or frequent need to work at elevation, unnatural ventilation, limited opening for entry and exit that may cause fatigue. According to Alasamri, Chrisp and Bowles (2012), for the management of health and safety, there is a need for effective and well structured policies so as to ensure the health and safety of employees in the oil and gas construction projects. There are several hazards that cause adverse effects on humans. Hazards includes chemical hazards such as carcinogen, irritant, toxic and corrosive, and physical hazards such as radiation, vibration and extreme temperature that might lead to several safety and health hazards (Sheikh, 2013).

The processes in the oil and gas industry have potential health effects, which are as follows: Agents such as drilling mud, radioactive sources, petroleum products, metals, chemicals, pathogenic microorganism might cause health effects such as stress, heart stroke, infection and parasitic diseases, cancer, spinal disorder, dermal and eye issues. According to Badiru and Osisanya, (2013), the oil and gas companies in Saudi Arabia have made several improvements in its health and safety management such as project monitoring, fire training, and modification of work permits. Several companies provide medical services in case of emergencies, as well as, companies also take steps in monitoring and preventing the oil spills (Alhajeri, 2011).

According to Husein (2013), legal authorities of Saudi Arabia employed some legal and regulatory policies that need to be followed by oil and gas construction industries (Karmis, 2001). It is essential that every employee in construction related projects should have health insurance. There are different legal arrangements such as Environmental Protection Standards (EPS) (1982), General Environmental Law (GEL) (2001), and Implementing Regulations (IR) (2003), which ensures the effective++ delivery of health and safety related regulations in the oil and gas construction related projects (Mitchell, Marcel and Mitchell, 2012).

\section{Recommendations}

In order to mitigate the factors that affect health and safety issues of oil and gas construction projects and 
Proc. of the Third Intl. Conf. on Advances in Management, Economics and Social Science - MES 2015.

Copyright (C) Institute of Research Engineers and Doctors, USA .All rights reserved.

ISBN: 978-1-63248-081-1 doi: 10.15224/ 978-1-63248-081-1-84

their impact on the concerned employees, some measures need to be taken by the industry. Some of the effective recommendations are given below:

Management, as well as, workers should align together and raise safety awareness, use safety gadgets and latest technologies to manage the health and safety issues (Brace, et al., 2009). Knowledge management practices, as well as, expert engineering practices should be involved (Ismail, Doostdar, and Harun, 2012). In construction safety management, some structural modifications need to be made where the focus should be placed on leading indicators so as to have advantages of total safety management (Agwu, 2012). Infrastructure should be improved and must be suitable for workers. Good management systems should be followed that will help the practical implementation of safety measures through leadership (Isosceles Group, 2014).

\section{v. Conclusion}

In order to develop an improved safety culture, it is essential that the oil and gas construction industries mitigate such factors that affect health and safety of their employees. There are several adverse effects that cause hazards to human lives. There is a drastic impact of the factors affecting the health and safety of employees; thus, some measures needs to be taken to establish a safe work environment. Knowledge management practices should be improved to keep the business process aligned with health and safety aspects of organisations.

\section{References}

[1] Agwu, M.O. 2012. Total Safety Management: A Strategy for Improving Organisational Performance in Selected Construction Companies in Nigeria. International Journal of Business and Social Science 3(20), pp. 210-217

[2] Alasamri, H., Chrisp, M.T. and Bowles, G. 2012. A Framework for Enhancing and Improving the Safety Culture on Saudi Construction Sites. Annual ARCOM Conference, pp. 475-485.

[3] Alhajeri, M. 2011. Health and safety in the construction industry: challenges and solutions in the UAE. [Online]. Available at: https://curve.coventry.ac.uk/open/file/8ef107a7-8740-4cb5ad55-07449f57cad4/1/Al\%20Hajeri\%202011.pdf [Accessed on: 30 June, 2015].

[4] Badiru, A.B. and Osisanya, S.O. 2013. Project management for the oil and gas industry: A world system approach. CRC Press.

[5] Brace, C., Gibb, A., Pendlebury, M. and Bust, P. 2009. Health and safety in the construction industry: Underlying causes of construction fatal accidents-External research. Loughborough University, pp. 1-204.

[6] Husein, A.T. 2013. Construction and projects in Saudi Arabia: overview. [Online]. Available at: http://www.dentons.com/ /media/PDFs/Insights/2013/Septembe r/Saudi\%20Arabiapdf.ashx [Accessed on: 30 June, 2015].

[7] Ismail, Z., Doostdar, S. and Harun, Z. 2012. Factors influencing the implementation of a safety management system for construction sites. Safety Science 50, pp. 418-423.

[8] Isosceles Group. 2014. Saudi Arabia Environment, Health \& Safety Profile and Checklist. [Online]. Available at: http://nimonik.com/case_studies/audit_previews/ksa_audit_previ ew_health_safety_environment.pdf [Accessed on: 30 June, 2015].

[9] Karmis, M. 2001. Mine health and safety management. SME.

[10] Mitchell, J., Marcel, V., and Mitchell, B. 2012. What Next for the Oil and Gas Industry? [Online]. Available at: http://www.chathamhouse.org/sites/files/chathamhouse/public/R esearch/Energy,\%20Environment\%20and\%20Development/101 2pr_oilgas.pdf [Accessed on: 30 June, 2015].

[11] Oloke D., Yu H. and Heesom D. 2007. Developing Practitioner Skills in Construction Health and Safety Management: An Integrated Teaching and Learning Approach. Journal for Education in the Built Environment (2)1, pp. 3-30.

[12] Sheikh, A.A. 2013. RFID for Oil and Gas Industry: Applications and Challenges. International Journal of Engineering and Innovative Technology (IJEIT), 3, pp. 80-85.

[13] Stellman, J.M. 1998. Encyclopaedia of Occupational Health and Safety: Chemical, industries and occupations. International Labour Organization.

[14] Stranks, J. 2010. Health and Safety at Work: An Essential Guide for Managers. : Kogan Page Publishers.

[15] Tam C.M., Zeng S.X., and Deng Z.M. 2004. Identifying elements of poor construction safety management in China. Safety Science 42(7), pp. 569-586. 